\title{
The Role of Mutual Support Groups for the Control of Diabetes in a Mexican City: Achievements and Limitations from the Patients' Perspective
}

\author{
Luz María Tejada-Tayabas, María Judith Rios Lugo \\ Faculty of Nursing, Autonomus University of San Luis Potosi, San Luis Potosí, México \\ Email: Itejada@uaslp.mx, judith.rios@uaslp.mx
}

Received 1 June 2014; revised 19 July 2014; accepted 8 August 2014

Copyright (C) 2014 by authors and Scientific Research Publishing Inc. This work is licensed under the Creative Commons Attribution International License (CC BY). http://creativecommons.org/licenses/by/4.0/

(c) (i) Open Access

\section{Abstract}

Background: Mutual Support Groups (MSG) provides to the patient, the ability to effective self-management behaviors, such as taking prescribed medications, following diet and exercise regimens, self-monitoring, and coping emotionally with the rigors of living with diabetes. Physicians, nurses and health promoters from public primary Health Care Centers (HCC) are responsible for providing follow-up care through MSGs. However, although the MSG program has been carried out, in the last decade Mexico presents the most alarming statistics in the prevalence and complications of Diabetes Mellitus type II (DM-II), suggesting a low impact of MSG in the strategy to support the effective control of the disease. Objetive: The aim of this work was to assess whether knowledge or benefits of effective management to control of DM-II, also to identify strengths and limitations of MSGs, in six different Health Care Centers (HCC), in San Luis Potosi, Mexico. This research provides an overview of patients' perception, and significant issues that demand to adjust MGSs strategies, with the goal of exceed the expectations of current health statistics. Methods: A qualitative evaluation was carried out, with an ethnographic approach design. The study included 28 diabetic persons, (21 women and 7 men from ruraland urban carecenters). Semistructured interviews, non-participant observation, and structured content analysis were used. Results: Support groups give patients a way to address emotional issues, and learn about their disease and self-care, although some patients consider participation an inconvenient obligation. Support group users mention barriers such as lack of continuity in support group activities, inconvenient meeting times, and the difficulty of commuting to attend group sessions. They also mention that overworked health care workers find it difficult to provide leadership to keep the group going. These issues have multiple implications for the success of strategies to control the disease. Conclusions: This study shows the need to apply a participatory model to disease support 
group strategies to reorganize their actions in such a way as to meet the needs and requirements of patients and to ensure their participation and help them control their disease.

\title{
Keywords
}

\author{
Mutual Support Group, Diabetes Mellitus, Qualitative Research, Health Care Services, Mexico
}

\section{Introduction}

Prevention and control of Diabetes Mellitus type II (DM-II) is a major challenge for health care systems worldwide. According to the World Health Organization (WHO), over 347 million people suffered DM-II in 2011, and by 2030, this could be doubled if no effective actions are undertaken [1]. Mortality in 2011 remained high with $1.7 \%$ of the world's population dying from diabetic complications [2]. The reported prevalence of DM-II in Mexico among individuals aged $>20$ years is $7.5 \%$, being the $12^{\text {th }}$ leading cause of morbidity [3] and the leading cause of overall mortality since 2006 [4]. Hospital-related cost estimation to treat DM-II complications will account for $\sim 2.6 \%$ of the gross domestic product in the coming years [5]. As part of the strategy to prevent and control DM-II and high blood pressure (HTN), in 1995, the Mexican health care system introduced the Mutual Support Groups (MSG) program [6] [7]. Studies show how MSGs increases knowledge about the disease, treatment adherence, and metabolic control among diabetic individuals [8]. MSG provides to the patient, the ability to effective self-management behaviors, such as taking prescribed medications, following diet and exercise regimens, self-monitoring, and coping emotionally with the rigors of living with diabetes [9]. Through MSG, patients are able to share experiences with others undergoing the same medical or behavioral tasks as an effective means of gaining mastery of tasks and improving disease outcomes. Moreover, the more likely support is usually with whom individuals identify and share, common experiences similar life experiences and age; leading to understanding, empathy, and mutual help [10] [11]. Authors have also shown that MSGs can support members controlling stressful psycho-social factors that can affect glucose levels in the short and long term [12]. Other studies have relied on qualitative methods to explore experiences and perceptions of diabetic individuals concerning the disease itself, as well as treatment modalities and lifestyle changes [13] [14]. While studies have shown that MSGs can have a positive effect on DM-II control. The operation of MSGs in primary health care settings has not been assessed from the "inside", namely, from the perspective of the group members. However, although the MSG program has been carried out, in the last decade it has been an alarming increase in the incidence and complications of DM-II, suggesting a low impact of MSG in the strategy to support the effective management of the disease. The aim of this work was to assess whether knowledge or benefits of an effective control of DM-II and its complications, were enhanced by Mutual Support Groups (MSG); and to identify strengths and limitations of MSGs in six different Health Care Centers (HCC) of San Luis Potosi, Mexico. In the current work, we studied practical issues that affect programs or policies in real settings, using the experiences and perceptions of the patients, with the objective of providing guide adjustments to improve MGSs.

\section{Methods}

\subsection{Design and Participants}

A Qualitative Evaluation (QE) [15] was carried out, using an ethnographic approach design [16], which was begun in September 2011 and finished on May 2012. This study was performed at six HCCs administered by the largest health jurisdiction of the Ministry of Health in San Luis Potosí State in central Mexico. Two of the centers were urban, two were rural and two served individuals living in both rural and urban areas.

Records for each HCC were reviewed to obtain data about the characteristics and context in which MSGs operate. Population coverage ranged from 2867 to 43,300 people, and the number of adults diagnosed with chronic conditions ranged from 269 to 1092 across the HCCs. The number of patients with a chronic disease attending MSG meetings averaged 28 (range 20 - 35), so that only 3\% of the diabetic patients registered joined the gatherings, which occurred daily, weekly, monthly, bimonthly and sporadically depending on the center (Table 1).

A purposive sample [17] of 28 persons with DM-II was selected (4 - 6 per center) to explore their perspective 
Table 1. Health care centers’ characteristics in qualitative assessment, San Luis Potosi, Mexico.

\begin{tabular}{|c|c|c|c|c|c|c|}
\hline \multirow{2}{*}{ Characteristic $^{1}$} & \multicolumn{6}{|c|}{ Health Care Center } \\
\hline & 1 & 2 & 3 & 4 & 5 & 6 \\
\hline Type of population served & Urban/Rural & Urban & Urban & Urban/Rural & Rural & Rural \\
\hline Population served & 4616 & 43,300 & 13,647 & 3514 & 2867 & 5635 \\
\hline Families per doctor or nurse & 500 & 500 & 500 & 500 & 500 & 500 \\
\hline Ratio of health professionals to population & $1: 673$ & 1:3300 & 1:720 & 1:1171 & $1: 1433$ & 1:1408 \\
\hline Patients with chronic diseases in control programs ${ }^{1}$ & 269 & 3464 & 1092 & 281 & 229 & 450 \\
\hline Patients with a chronic disease who attend MSGs & 30 & 23 & 27 & 33 & 20 & 35 \\
\hline Doctor and nurses assigned to the health center & 5 & 13 & 19 & 3 & 2 & 4 \\
\hline Frequency of MSG meetings & Weekly & Monthly & Daily & Sporadic & Bimonthly & Sporadic \\
\hline
\end{tabular}

${ }^{1}$ Includes diabetes mellitus and hypertension.

concerning the operation of MSGs. Inclusion criteria comprised having DM-II diagnosis and attending MSG regardless of the frequency. The health workers perspectives were investigated and will be presented in another publishing.

\subsection{Data Collection}

Semi-structured interviews following a guide (Table 2) were conducted including: 1) Conceptualization of MSG; 2) Reasons for attending MSGs; 3) Benefits of participating in MSGs; 4) MSG activities; and 5) Evaluation of MSGs. Only one interview was conducted per participant. Interviews were carried out consecutively and parallel to the analysis until data saturation was reached. Interviews lasted approximately 60 minutes, were audio-recorded, and then transcribed following standard guidelines. The individual interview was chosen because it allows participants to express their views more freely. The interviews were performed in a separate room of the health centers so it was possible for respondents to express themselves freely.

\subsection{Data Analysis}

Conventional content analysis [18] was used to analyze and interpret the data. Both authors of this article participated in this process. The procedures involved comprised the following: 1) Systematic verbatim transcription of interviews; 2) Detailed reading of transcripts, and initial coding to identify relevant topics; 3) Pooling of codes to build a unified comprehensive coding scheme; 4) Additional coding based on the resulting scheme aimed at recognizing commonality and variability in the narratives to identify collective shared concepts and basic ideas (done by the first author only); 5) Discussion of results between the researchers; and 6) Presentation of final results to various informants in order to verify the findings [19]. The Atlas Ti 5.2 software was used to carry out the analysis.

All informants involved provided verbal informed consent. Ethical principles concerning autonomy, self-determination and data confidentiality were followed. The Ethics Committee at the Mexican Ministry of Health approved the project.

\section{Results}

The MSGs program comprises monitoring and management of DM-II and HTN among adults diagnosed with these conditions. Physicians, nurses and health promoters from public primary Health Care Centers (HCC) are responsible for operating the MSGs. HCCs within public institutions organize MSGs based on the operational criteria outlined by the Ministry of Health and the Mexican Official Norm for the prevention, treatment and management of DM-II.

The MSGs strategy is strengthened by the "Oportunidades" program, which in general delivers conditional financial support to poor families, but in this specific context to adults suffering from DM-II, HTN or another 
Table 2. Interview guide used in the qualitative assessment of Mutual Support Groups (MSGs).

\begin{tabular}{ll}
\hline \multicolumn{1}{c}{ Topic assessed } & \multicolumn{1}{c}{ Questions asked } \\
\hline $\begin{array}{l}\text { Conceptualization of MSG } \\
\text { Reasons for attending MSGs }\end{array}$ & What is a Mutual Support Groups for you? \\
Benefits of participating in MSGs & Why do you attend a Mutual Support Groups? \\
& $\begin{array}{l}\text { Has attending Mutual Support Groups sessions helped you, and if so how? } \\
\text { Could you tell me about the Mutual Support Groups activities? }\end{array}$ \\
MSG activities & $\begin{array}{l}\text { What activities have been helpful to you and why? } \\
\text { What difficulties have you faced regarding Mutual Support Groups activities? }\end{array}$ \\
& $\begin{array}{l}\text { What do you like most about the Mutual Support Groups? } \\
\text { Wvaluation of MSGs }\end{array}$ \\
& $\begin{array}{l}\text { What do you think could be improved in the Mutual Support Groups? } \\
\text { others not so much, what is your experience? }\end{array}$ \\
\hline
\end{tabular}

chronic disease, (arthritis, tuberculosis) provided that they participate in MSGs.

Within the respondents, the majority of persons $(n=20)$ were aged 50 years or more, 21 were female housewives, and 23 lived in vulnerable conditions reflected by an income of $\sim 30$ USD per week. The proportion of local and out-of-town patients was similar. 11 respondents inhabited rural areas (Table 3). Among the patients interviewed, some attended MSG meetings regularly and others sporadically, with the latter attending HCCs located in rural areas, and it was mostly these rural patients who had negative views about the MSGs.

\subsection{Conceptualization of MSG}

Most of the patients interviewed considered the MSG as a meeting where they attend "talks". They associated these meetings with the Oportunidades program run by the Ministry of Health.

A few respondents considered the MSG as a support network to empower patients to perform self-care activities, and to help them dealing with the disease.

... I have been to several health centers and yes, people with hypertension and diabetes go to these groups; they do exercises and crafts, but here they only have these meetings to give us talks ... (Female patient from a rural HCC)

... It's a group where we all help each other, so you don't feel you're alone; it helps you feel more relaxed if you talk with other people about your things. If someone has a problem, then you start to discuss different solutions to the problems you have with a disease like this. Besides, you know that it will get worse ... (Female patient from a rural/urban $\mathrm{HCC}$ )

\subsection{Reasons for Attending MSGs}

Some patients perceived an "obligation" to attend group meetings as a condition to continue receiving the financial benefits of the Oportunidades program. Two women attending rural HCCs mentioned about that.

... when they come to distribute the Oportunidades [program] aid, they have a meeting first, they give talks, and then they schedule us to come back the next week, which is when they will tell us when they are going to give us the Oportunidades money. That's what I mean when I say that they force us to go. I have been told that my responsibility is to go so they can give me a check-up, and also to go to the talks, so that's why I go ... (Female patient from a rural HCC)

Other patients reported that they were interested in learning about their illness and to learn about how to take care of themselves. Some reported attending MSGs to improve their physical and mental well-being and also because they considered that sharing and communicating with other members could be valuable.

... for me it's important to attend the group sessions because you learn a lot about your disease, about the drugs we take, and about how we should care for ourselves so we don't get further problems; you also learn [about] what you should and shouldn't eat, and the symptoms we could get when we take our insulin and what to do in each case ... (Male patient from an urban HCC)

\subsection{Barriers to Participate in MSGs}

Some patients faced barriers to attend MSG meetings, such as the distance from their home to the HCC, which 
Table 3. Participants characteristics.

\begin{tabular}{|c|c|c|}
\hline Variable & Category & Participants \\
\hline \multirow{4}{*}{ Age in years } & $31-40$ & 4 \\
\hline & $41-50$ & 4 \\
\hline & $51-60$ & 8 \\
\hline & $>60$ & 12 \\
\hline \multirow{3}{*}{ Sex } & Male & 7 \\
\hline & Female & 21 \\
\hline & Married & 18 \\
\hline \multirow{4}{*}{ Marital status } & Cohabiting & 7 \\
\hline & Separated & 1 \\
\hline & Widowed & 1 \\
\hline & Single & 1 \\
\hline \multirow{4}{*}{ Occupation } & Housewife & 19 \\
\hline & Informal merchant & 5 \\
\hline & Worker & 1 \\
\hline & Retired & 1 \\
\hline \multirow{4}{*}{ Place of origin } & Unemployed & 2 \\
\hline & City of San Luis Potosí & 14 \\
\hline & Rural Community & 11 \\
\hline & Other Mexican State & 3 \\
\hline \multirow{3}{*}{ Weekly income in Mexican pesos } & $<300$ & 12 \\
\hline & $300-499$ & 11 \\
\hline & $500-100$ & 5 \\
\hline \multirow{2}{*}{ Chronic disease } & DM & 18 \\
\hline & $\mathrm{DM}+\mathrm{HTN}$ & 10 \\
\hline \multirow{3}{*}{ Years with DM (DM + HTN) } & $2-10$ & $7(3)$ \\
\hline & $11-20$ & $7(3)$ \\
\hline & $21-30$ & $4(4)$ \\
\hline \multirow{3}{*}{ Health service provider } & Social security insurance & 5 \\
\hline & Popular health insurance & 19 \\
\hline & Oportunidades program & 10 \\
\hline \multirow{4}{*}{ Health institution attended } & HCC outside their district & 3 \\
\hline & Central hospital & 18 \\
\hline & Private clinics & 16 \\
\hline & Mexican Institute of Social Security & 3 \\
\hline
\end{tabular}

makes transportation difficult, a situation that becomes particularly relevant for those with physical limitations often resulting from diabetic complications. Patients who had experienced this problem expressed the following: ... to tell the truth, I don't go to the group because the health center is too far, and I can't take the bus alone; I don't have anyone who can come with me, and I can't afford to pay a taxi, so I end up not going, though I would like to ... (Female patient from an urban HCC) 
Another barrier reported was the time of day when the sessions are held, which may overlap with working hours or home duties. This prevents some people attending regularly, as one participant puts it:

... I would like to go, but I can't because of my work. I have to take time off to go to an appointment, and this is hard because then I don't get paid ... the meetings are always in the mornings, but in the afternoon, when I would be able to go, it's not when the group meets. They should have different meeting times so that you could choose when you attend. (Male patient from a rural/urban HCC)

\subsection{Benefits of Participating in MSGs}

Some urban patients reported that MSGs give them both physical and emotional benefits. They mentioned that they had lost weight, and were able to control their blood sugar and arterial pressure. Patients reported that the sessions have helped them improve their mood and cope with their disease better. Two females who regularly attend urban meetings expressed the following:

... a group like this helps us as patients. If you're diabetic or hypertensive you have a lot of physical problems, you're deteriorating. Participating in discussions, doing the exercises, and meeting with the others encourages you to keep on going and to become better ... (Female patient from an urban HCC)

\subsection{MSG Achievements}

Most patients attending urban and rural/urban HCCs considered the talks on various topics related to their disease useful. They reported that the blood sugar and arterial pressure monitoring was helpful. Two patients attending urban MSG meetings comented:

... the talks they organize in the groups help us because we are not used to the words the doctors often use; in the talks they tell us what these words mean, and this helps a lot. (Female patient from an urban HCC)

Only the urban HCCs have physical activity sessions at their MSGs. The patients considered the activity sessions a great success. They mentioned that they keep them active and help to control their blood sugar:

... in the group we do exercise with the others, it motivates you more; when it's just you, you don't do any (exercise). Every day, the group gets together to do exercise, and if you go regularly you feel much better, it's really good that they keep us active ... (Female patient from an urban HCC)

Another relevant success is the participation of psychologists in the MSGs; patients have both individual and group sessions with them. They support patients by addressing emotional issues associated with the disease, as reported by one of the participants:

It's really good that we have a psychologist because sometimes you need to talk about what you are feeling. At times, I get depressed and talking with him has helped me. I would say that the psychologist should be there more time to help us ... (Female patient from an urban HCC)

\subsection{Limitations of MSGs}

The main limitations expressed by the participants relate to the talks conducted. Some talks seem to have little value. Also, the lack of continuity of the group sessions and activities could be confusing, discouraging patients from attending. As some participants expressed it:

... we go, but we get tired of going because they tell us to come back every week, and it can be a long wait before the talk begins, and sometimes there wasn't even anything ... (Female patient from a rural/urban HCC)

Sometimes I think the talks are not very helpful because, actually, you don't understand a lot and we forget what they tell us ... (Male patient from a rural HCC)

Some patients also mentioned that MSGs are not as well organized because the groups have no coordinator responsible for the continuity of the activities. They thought that the staff at the HCCs was too busy, which prevented them from taking care of the MSGs; yet, organizers do not encourage greater patient participation. One woman referred to this topic as follows:

... What I've noticed is that nurses and doctors have a lot of work; sometimes they are overloaded with all the patients they see, children, women, men, seniors; so even if they wanted to, how would they have time to take care of the group too? But they don't ask us for help either; some of us could help with organizing the group if they would ask us ... (Female patient from an urban HCC). More Support segments of interviews to see Figure 1. 
... I go to the talks because you have to, if I don't go they mark me absent and withdraw the support I get from the Oportunidades [program], but to be honest, it does help even though it's just a little bit. The lady tells us we don't have to, but I do feel obliged. I have no other option than to go on the day and at the time that they say ... (Female patient from a rural HCC)

... for me it's important to attend the group sessions because you learn a lot about your disease, about the drugs we take, and about how we should care for ourselves so we don't get further

Reasons for attending MSGs

Barriers to participate in MSGs

Benefits of participating in MSGs

MSG achievements

Limitations of MSGs problems; you also learn [about] what you should and shouldn't eat, and the symptoms we could get when we take our insulin and what to do in each case ... (Male patient from an urban HCC)

... I think that being in the group motivates us to take better care of ourselves, seeing other patients with all their problems and the effort they have to put into their care motivates you; in this way we support each other ... (Female patient from an urban HCC)

... what I really like about it is that you always learn something new, everything I'm learning I tell my sisters, because I know that sooner or later they might become diabetic too, so that they can gradually start taking care of themselves ... (Male patient from an urban HCC)

... to tell the truth, I don't go to the group because the health center is too far, and I can't take the bus alone; I don't have anyone who can come with me, and I can't afford to pay a taxi, so I end up not going, though I would like to ... (Female patient from an urban HCC)

... I don't participate [in the MSG], or do very little, because I had a heart attack and I can't walk much. When I attend, it's because I have questions or I feel bad. Then I stay in the [MSG] meeting, but not very often because I don't have anyone who can come with me, and in the condition I am in I can't go alone ... (Female patient from an urban HCC)

... I would like to go, but I can't because of my work. I have to take time off to go to an appointment, and this is hard because then I don't get paid ... the meetings are always in the mornings, but in the afternoon, when I would be able to go, it's not when the group meets. They should have different meeting times so that you could choose when you attend. (Male patient from a rural/urban HCC)

... a group like this helps us as patients. If you're diabetic or hypertensive you have a lot of physical problems, you're deteriorating. Participating in discussions, doing the exercises, and meeting with the others encourages you to keep on going and to become better ... (Female patient from an urban $\mathrm{HCC}$ )

... being in the group has helped me a lot; I feel better. I've lost weight and my blood sugar is under better control. I also feel more energetic. Here [in the MSG] you can talk about your problems, and even more so when the psychologists come and you start talking. You talk about your concerns and about the things that make you sad ... (Female patient from an urban HCC)

... the talks they organize in the groups help us because we are not in used to the words the doctors often use; in the talks they tell us what do these words mean, and this helps a lot. (Female patient from an urban $\mathrm{HCC}$ )

In the group, they monitor your blood sugar to check whether we have it under control or not. Every month or so they do a blood test and take our blood pressure so they can tell the doctor how we are doing. In this way, when we go to the appointment the doctor knows how we were in the previous month. (Female patient from an urban HCC)

... in the group we do exercise with the others, it motivates you more; when it's just you, you don't do any (exercise). Every day, the group gets together to do exercise, and if you go regularly you feel much better, it's really good that they keep us active ... (Female patient from an urban HCC)

It's really good that we have a psychologist because sometimes you need to talk about what you are feeling. At times, I get depressed and talking with him has helped me. I would say that the psychologist should be there more time to help us ... (Female patient from an urban HCC)

... we go, but we get tired of going because they tell us to come back every week, and it can be a long wait before the talk begins, and sometimes there wasn't even anything ... (Female patient from a rural/urban $\mathrm{HCC}$ )

Sometimes I think the talks are not very helpful because, actually, you don't understand a lot and we forget what they tell us ... (male patient from a rural HCC)

There are activities that help us a lot, but the problem is that they hardly ever have those; you could say that it was only once in a while that they have exercise classes, around every two or three months. What they have more often is the talks. (Male patient from an urban HCC)

What I've noticed is that nurses and doctors have a lot of work; sometimes they are overloaded with all the patients they see, children, women, men, seniors; so even if they wanted to, how would they have time to take care of the group too? But they don't ask us for help either; some of us could help with organizing the group if they would ask us ... (Female patient from an urban HCC)

... they give us brochures and leaflets with information that I guess is important, but I one can't read them because I can't see very well and the letters are very small, so what good does it do me? ... (Male patient from a rural HCC) 
With respect to the printed material (brochures) containing information about the disease and self-care, older patients stated that they could not read them easily; they considered them unsuitable for this reason. Figure 1, shows another support segment of interviews with informants.

\section{Discussion}

This study aimed at examining the operational achievements and limitations of MSGs from the perspective of diabetic patients at six HCCs located in the city of San Luis Potosi. The results showed that MSGs improve the patients' physical, emotional and social well-being, reinforce healthy habits, provide a support network, and help maintain the patients' metabolic control. Operational difficulties that affected the MSG attendance of participants included irregular programing of activities, work overload that restricted HCC staff from offering reliable leadership, problems implementing a more inclusive and participatory strategy, and lack of clarity regarding the aims and value of the MSGs.

It is worth noting that perceived MSG benefits and successes were mostly reported by patients who attended urban HCCs. Conversely, limitations were more often mentioned by those from rural/urban settings. MSG activities seemed to be better organized in urban centers while personnel shortage to fully develop the MSG strategy appeared to be a recurrent concern in the rural centers, a finding matching the smaller number of health care workers available at rural HCCs. The fact that staff has to deliver primary health care services (32 programs) to patients, and not only those activities related to the control of chronic diseases, needs to be acknowledged to better contextualize the importance of personnel shortage.

The MSG benefits perceived by participants of this study were similar to those documented previously [20] [21]. There were positive remarks in terms of treatment adherence, metabolic control, and coping with the disease as other authors have reported [22], which translated into an improved quality of life.

The limited patient participation in MSGs together with the negative opinions concerning the operation of groups needs to be highlighted. For instance, the design and implementation of the self-help strategy seemed to be decided from a health professional standpoint paying little attention to the patients' perspective; this concern was particularly evident in HCCs serving rural populations.

The barriers to attend MSGs expressed by some respondents illustrate the gap between the planned strategy and the patients' actions. This resulted from overlooking the specific needs of patients with accessibility limitations, as previously reported among patients suffering from chronic conditions [23] [24].

It was also observed that the assistance provided by the Oportunidades program conditional on MSG attendance had only been partially effective in ensuring patient participation, as only a very small proportion of those receiving support attended group meetings. It is therefore essential to identify attendance determinants to guarantee a minimum participation. In addition to the adverse conditions in which many patients live and the difficulties confronted to attend group meetings in spite of recognizing their benefits, patients also reported institutional barriers, such as irregular activity schedules, lack of personal attention, and inadequate leadership of the groups. All these factors need to be seriously considered when redesigning and carrying out MSGs in the future to be able to improve patients' attendance.

Some studies have used self-directed approaches to develop health care programs that promote support groups, which integrate the patients' own experiences, meanings and concerns. This approach has proven successful encouraging patients to incorporate lifestyle changes, and even motivating participants to continue attending meetings after completing the program and despite transportation barriers [22].

\section{Conclusions}

The way in which the MSG strategy has been implemented across the HCCs studied revealed various benefits and successes, but also operational limitations that explain why MSGs have not achieved the proven effectiveness for developing patients' adherence to comprehensive DM-II treatment. This study shows the need to implement a participatory model as other authors have suggested [25] [26], which takes into consideration the patients' access possibilities, as well as their needs and expectations. It has been seen that involving patients directly in the organization and implementation of activities translates into a greater sense of ownership and responsibility, which eventually results in greater MSG sustainability and autonomy without generating excessive costs for the health care system. This approach also has the potential to reduce the demand for services releasing staff time to be allocated to other relevant primary health care activities. 
The results of this study do not reflect the situation of MSGs elsewhere in the state or other parts of Mexico; they mirror the specific characteristics of the MSG implementation at six HCCs located in San Luis Potosi. However, findings allowed for the identification of strengths and weaknesses associated with the operation of MSGs.

Given the scarcity of qualitative evaluations of health programs in Latin America, some of the results of this study may offer guidance for expanding the analysis of the conditions and quality under which primary care programs operate, so that the perspective of the stakeholders can be considered.

\section{References}

[1] World Health Organization (2014) Health Topics. 10 Data about Diabetes. http://www.who.int/features/factfiles/diabetes/es/index.html

[2] World Health Organization (2011) Global Status Report on Noncommunicable Diseases 2010. World Health Organization, Geneva.

[3] Villalpando, S., De la Cruz, V., Rojas, R., Shama-Levt, T., Avila, M.A., Gaona, B., et al. (2010) Prevalence and Distribution of Type 2 Diabetes Mellitus in Mexican Adult Population. A Probabilistic Survey. Salud Pública de México, 52, S19-S26. http://dx.doi.org/10.1590/S0036-36342010000700005

[4] Roglic, G., Unwin, N., Bennett, P.H., Mathers, C., Tuomilehto, J., Nag, S., et al. (2005) The Burden of Mortality Attributable to Diabetes. Diabetes Care, 28, 2130-2135. http://dx.doi.org/10.2337/diacare.28.9.2130

[5] Arrendondo, A. and De Icaza, E. (2009) Financial Requirements for the Treatment of Diabetes in Latin America: Implications for the Health System and for Patients in Mexico. Diabetología, 52, 1693-1695. http://dx.doi.org/10.1007/s00125-009-1417-5

[6] Ministry of Health (2006) Mutual Aid Groups: Technical Guide for Operation 2006. Ministry of Health of Mexico, Mexico City.

[7] Ministry of Health (2008) Undersecretary of Prevention and Health Protection. Specific Action Program 2007-2012 Diabetes Mellitus. Ministry of Health, Mexico City.

[8] Naik, A.D., Palmer, N., Petersen, N.J., Street, R.L., Rao, R., Suarez-Almazor, M., et al. (2011) Comparative Effectiveness of Goal Setting in Diabetes Mellitus Group Clinics: Randomized Clinical Trial. Archives of Internal Medicine, 171, 453-459. http://dx.doi.org/10.1001/archinternmed.2011.70

[9] PharmD, D.K., Melkus, G.D., Mickey, P., Stuart, W., McKoy, J.M., Urbanski, P., et al. (2013) Reducing the Risks of Diabetes Complications through Diabetes Self-Management Education and Support. Population Health Management, 16, 74-81. http://dx.doi.org/10.1089/pop.2012.0020

[10] Lerma, I., López-Ponce, A., Villa, A.R., Escobedo, M., Caballero, E.A., Velasco, M.A., et al. (2009) Pilot Study Two Different Strategies to Enhance Self-Care Behaviors and Treatment Adherence in Low-Income Patients with Type 2 Diabetes. Gaceta Medica de México, 145, 15-19.

[11] Schillinger, D., Wang, F., Handley, M. and Hammer, H. (2009) Effects of Self-Management Support on Structure, Process, and Outcomes among Vulnerable Patients with Diabetes. A Three-Arm Practical Clinical Trial. Diabetes Care, 32, 559-566. http://dx.doi.org/10.2337/dc08-0787

[12] Sapag, J.C., Lange, I., Campos, S. and Piette, J.D. (2010) Innovative Care and Self-Care Strategies for People with Chronic Diseases in Latin America. Revista Panamericana de Salud Pública, 27, 1-9.

[13] Lawton, J., Peel, E., Parry, O. and Douglas, M. (2008) Patients’ Perceptions and Experiences of Taking Oral Glucose Lowering Agents: A Longitudinal Qualitative Study. Diabetic Medicine, 25, 491-495. http://dx.doi.org/10.1111/j.1464-5491.2008.02400.x

[14] Beverly, E.A. and Wray, L.A. (2010) The Role of Collective Efficacy in Exercise Adherence: A Qualitative Study of Spousal Support and Type 2 Diabetes Management. Health Education Research, 25, 211-223. http://dx.doi.org/10.1093/her/cyn032

[15] Patton, M.Q. (2002) Qualitative Research and Evaluation Methods. Sage Publications Ltd, Thousand Oaks.

[16] Cook, K. (2005) Using Critical Ethnography to Explore Issues in Health Promotion. Qualitative Health Research, 15, 129-138. http://dx.doi.org/10.1177/1049732304267751

[17] Marshall, M.N. (1996) Sampling for Qualitative Research. Family Practice, 13, 522-525. http://dx.doi.org/10.1093/fampra/13.6.522

[18] Hsieh, H.F. and Shannon, S. (2005) Three Approaches to Qualitative Content Analysis. Qualitative Health Research, 15, 1277-1288. http://dx.doi.org/10.1177/1049732305276687

[19] Silverman, D. (2003) Doing Qualitative Research. Sage Publications, Thousand Oaks. 
[20] Chaveepojnkamjorn, W., Pichainarong, N., Schelp, F.P. and Mahaweerawat, U.A. (2009) Randomized Controlled Trial to Improve the Quality of Life of Type 2 Diabetic Patients Using a Self-Help Group Program. The Southeast Asian Journal of Tropical Medicine and Public Health, 40, 169-176.

[21] Douglas, R. (2011) Design of a Rural Diabetes Self-Directed Care Program. Social Work in Health Care, 50, $775-786$. http://www.tandfonline.com/doi/pdf/10.1080/00981389.2011.597496

[22] Hale, N., Bennett, K. and Probst, J. (2010) Diabetes Care and Outcomes: Disparities across Rural America. Journal of Community Health, 35, 365-374. http://dx.doi.org/10.1007/s10900-010-9259-0

[23] Tejada-Tayabas, L.M. (2010) Between the Availability and Accessibility to Health Care. The Perspective of Patients with Chronic Diseases Living in Poverty. Salud Colectiva, 6, 35-45. http://dx.doi.org/10.1590/S1851-82652010000100004

[24] Costello, J.F. (2013) Roles and Strategies of Diabetes Support Group Facilitators: An Exploratory Study. The Diabetes Educator, 39, 178-186. http://tde.sagepub.com/content/39/2/178 http://dx.doi.org/10.1177/0145721713476347

[25] Sukwatjanee, A., Pongthavornkamol, K., Suwaonnaroop, N., Pinyopasakul, W., Low, G. and Chokkhanchitchai, S. (2009) Enhancing Self-Care Ability and Quality of Life among Rural-Dwelling Thai Elders with Type 2 Diabetes through a Self-Help Group: A Participatory Action Research Approach. International Journal of Behavioral Science, 4, 84-91.

[26] Hillstrom, K., Ruelas, V., Peters, A., Gedebu-Wilson, T. and Iverson, E. (2014) A Retrospective Analysis of the Capacity Built through a Community-Based Participatory Research Project Addressing Diabetes and Obesity in South and East Los Angeles. Health, 6, 1429-1435. http://www.scirp.org/journal/health http://dx.doi.org/10.4236/health.2014.612175 
Scientific Research Publishing (SCIRP) is one of the largest Open Access journal publishers. It is currently publishing more than 200 open access, online, peer-reviewed journals covering a wide range of academic disciplines. SCIRP serves the worldwide academic communities and contributes to the progress and application of science with its publication.

Other selected journals from SCIRP are listed as below. Submit your manuscript to us via either submit@scirp.org or Online Submission Portal.
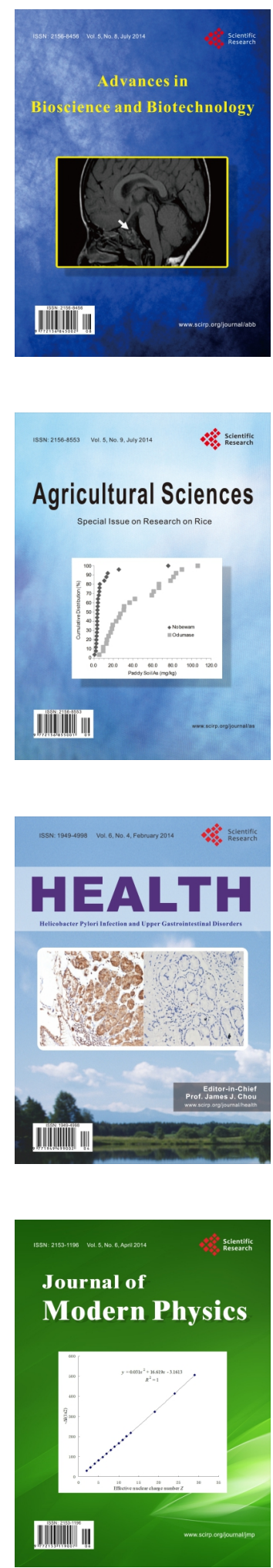
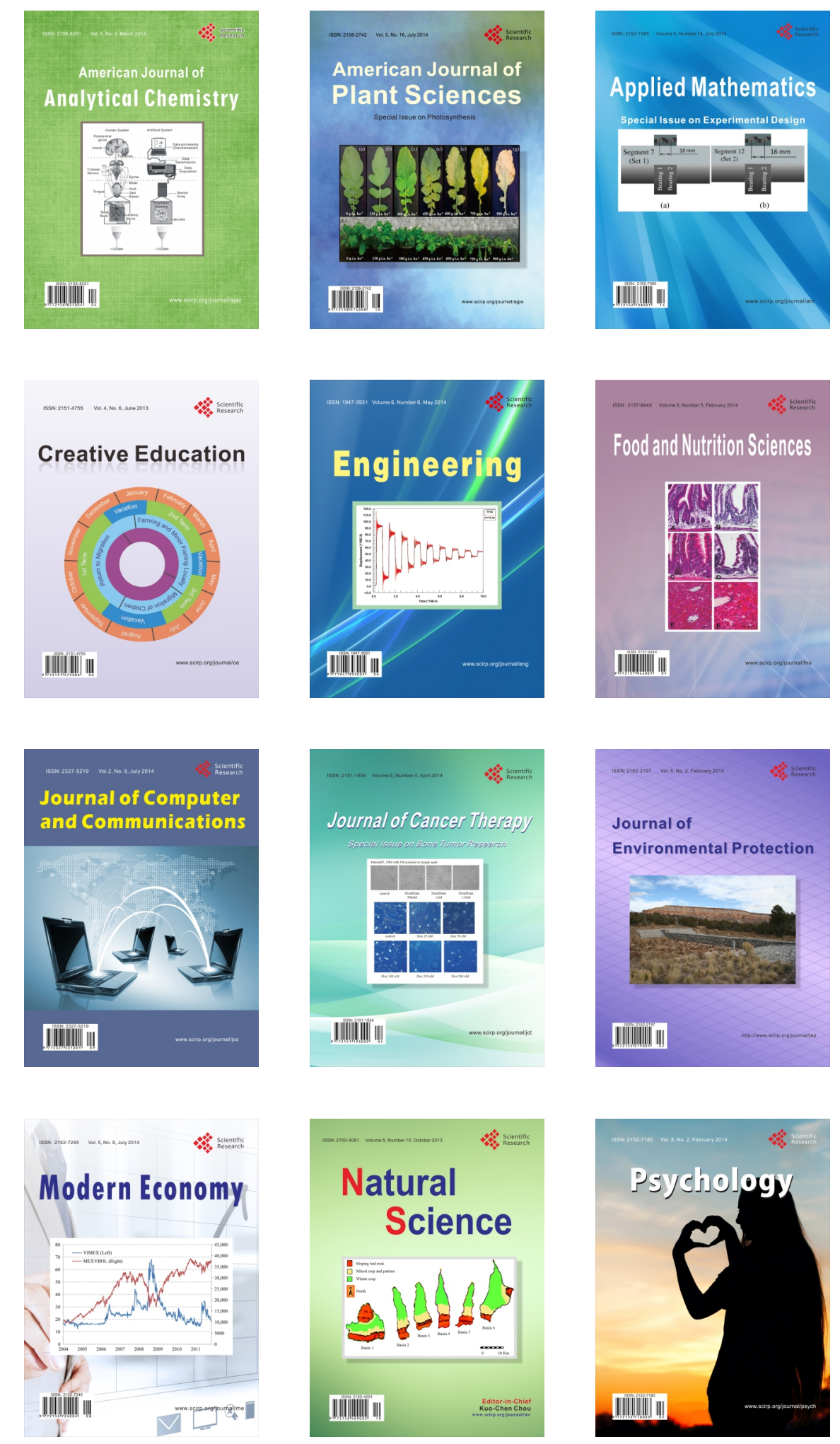